\title{
Does Kashin-beck Disease Present Only Multisite Pain? A Cross-sectional Study of Pain Characteristics in Northwest China
}

\section{Dimiao Wang}

School of Nursing, Health Science Center of Xi'an Jiaotong University

\section{Mohammad Imran Younus}

Deputy District Officer Health Taxila, District Rawalpindi

Chao Xu

Linyou Hospital of Traditional Chinese Medicine,Shaanxi Province

Hua Fang

School of Nursing, Health Science Center of Xi'an Jiaotong University

Huan Liu

School of Public Health, Health of Science of Xi'an Jiaotong University

Xiong Guo ( $\nabla$ guox@mail.xjtu.edu.cn )

xi'an jiaotong university https://orcid.org/0000-0003-4413-5022

Research article

Keywords: Kashin-Beck disease, pain characteristics, associated factors, cross-sectional study

Posted Date: September 25th, 2020

DOI: https://doi.org/10.21203/rs.3.rs-79403/v1

License: (c) (i) This work is licensed under a Creative Commons Attribution 4.0 International License. Read Full License 


\section{Abstract}

Background

Kashin-Beck Disease (KBD) is an endemic, chronic joint disease. Multisite joint pain is the primary symptom of KBD, which have profound negative effects on individuals and society. However, studies on joint pain characteristics among the KBD population are still limited. The aims of this study were to explore characteristics of joint pain in patients with KBD and determine associated factors with joint pain.

Methods

This cross-sectional study included 167 patients with KBD and 169 patients from the general population with joint pain from Shaanxi Province in northwest China. Subjects were asked about joint pain characteristics and completed the numeric rating scale (NRS), the graded chronic pain scale (GCPS) and the EuroQol (EQ-5D) questionnaire. Differences between groups were determined using Chi-square, Student's t, Mann-Whitney U and 1-way ANOVA tests.

Results

Compared with the general group, patients with KBD reported a higher number of pain sites (7.2 \pm 3.8 vs $3.5 \pm 1.8)$, a higher frequency of persistent pain ( $98.8 \%$ vs $50.9 \%$ ), a higher percentage of analgesics usage ( $89.2 \%$ vs $30.7 \%)$, a higher pain intensity $(73.8 \pm 15.2$ vs $50.0 \pm 20.7)$ and pain - related disability (61.2 \pm 23.3 vs $41.6 \pm 23.2)$, and lower EQ-5D scores $(0.34 \pm 0.27$ vs $0.59 \pm 0.16)$. Among the $167 \mathrm{KBD}$ patients, painful joints were symmetrically distributed between the bilateral limbs; the 5 most frequently reported painful joints for the bilateral sides were the knees (84.8\%), ankles (79.2\%), wrists (51.2\%), shoulders (49.5\%) and elbows (47.7\%). The most severe pain joint was the knee (NRS:6.6), followed by the ankles (NRS:5.1), the fingers, shoulders and elbows had the similar NRS scores (NRS:4.0). Additionally, KBD patients experienced neuropathic pain to varying degrees. Compared to males, females reported a higher number of total pain sites, higher intensity and lower quality of life.

\section{Conclusions}

Besides multisite pain, the KBD patients suffered from symmetrical, persistent, and neuropathic pain. Weight-bearing joints (e.g., knee and ankle) were the most painful. These findings will provide scientific basis for establishing joint pain evaluation criteria and future pain intervention strategies for these KBD patients in China.

\section{Background}

Kashin-Beck disease (KBD) is a severe osteoarthropathy of unknown cause that is endemic, ranging from Russia, the north of Korea and the northeast to the southwest of China [1]. Three interacting causal mechanisms have been proposed, including a selenium deficiency, contamination of food by mycotoxins, and organic matter in contaminated drinking water [2]. Currently, it has been widely accepted that KBD is a result of environment-gene interaction [3]. KBD occurs most commonly in children aged 5-13 years and is characterized by the degeneration and necrosis of epiphyseal plate cartilage as well as articular cartilage at several other locations in the developing skeleton $[4,5]$. It currently affects 22,567,600 inhabitants, and there were 574,925 patients in 2016 [6].

Clinically, the primary symptoms of KBD include multisite joint pain, morning stiffness, enlarged and shortened fingers, and deformed and enlarged joints with limited motion in the extremities [7]. Joint pain has been shown to have profound negative effects on individuals and society[8]. It is reported that the prevalence rates of joint pain varied from $58 \%$ to $97.5 \%$ in $\mathrm{KBD}$ patients $[9,10]$. This value is extremely high but, unfortunately, data on the characteristics of $\mathrm{KBD}$ 
joint pain is scarce. Previous studies on the KBD clinical symptoms mainly focused on the enlargement, deformation, and dysfunction of joints in limbs and radiological lesions of the right hand [11]. Although some studies have reported that KBD patients experienced multisite and bilateral joint pain[9, 12], while others have reported the pain intensity of specific joint in KBD patients (e.g., knees and elbows) [10], they did not provide more information on pain characteristics, such as the frequency and the number of painful joints. Although pain intensity is the most common pain domain assessed in research and clinical practice, pain intensity measures are suboptimal for distinguishing the effects of two active treatments[13].Knowledge of intensity, frequency, duration, site, quality and associated factors of joint pain gives a complete picture of the symptom. However, no study has addressed simultaneously these questions in KBD patients. Thus, the characteristics of KBD pain remain poorly understood. Our incomplete understanding of joint pain characteristics is a barrier to provide appropriate clinical treatment for KBD.

Currently, relieving the pain is an important target in the treatment of KBD [14]. However, pain treatment for KBD is mainly derived from experiences of osteoarthritis (OA) [15], including the administration of analgesic drugs [5], selenium supplementation [16], intra-articular injections of hyaluronic acid (IAHA) [14], surgical procedures[17, 18] and physical therapy [19]. Despite various treatment approaches, there is no specific disease pain measurement to assess joint pain after treatment. A sound pain assessment is an indispensable first step in the management of patients with pain. Thus, it is urgent to resolve this problem.

Our understanding of joint pain characteristics is a necessary prerequisite toward the development of a pain measurement tool and intervention strategies that can effectively address the joint pains of KBD patients. To our knowledge, there are very few studies focusing on KBD joint pain characteristics. Therefore, the purposes of this study were to detail the pain characteristics (e.g., pain intensity, pain frequency, pain location, pain interference, pain treatments) of KBD, and to determine which demographics were associated with pain characteristics. In so doing, it is anticipated that findings from this study will provide scientific basis for establishing joint pain evaluation criteria and future pain intervention strategies for KBD patients in China.

\section{Methods}

\section{Setting}

This study was conducted in Shaanxi Province in northwest China between May 2018 and October 2018. This is one of the regions with the most cases of KBD in China [20]. Two counties (Yongshou and Linyou) were randomly selected from total 62 endemic counties of Shaanxi Province. In the two counties, 6 villages of each county were selected randomly, and every available adult in these villages were invited to participate in this study.

\section{Diagnostic criteria of KBD}

In 2010, the National Health and Family Planning Commission of the People's Republic of China issued new Diagnostic Criteria for Kashin-Beck Disease (Diagnostic code: WS/T207-2010) [21]. The criteria of KBD include: a history of living in a KBD prevalent area, clinical manifestations (typically, short fingers, enlargement of finger joints, flexion of the distal finger and deformed fingers in hands) and radiography of the right hand (typically, irregular sclerosis and reappearance of a calcification zone in the metaphysis of the metacarpus and phalange). The diagnostic grade criteria for grading were as follows: Grade I, enlarged finger joints, limited motion and pain in the joints of the limbs; Grade II, shortened fingers and clinical symptoms of the first stage; and Grade III, dwarfism and clinical symptoms of the second stage.

\section{Sample size calculation}

Page $3 / 22$ 
The present study included a sample of patients with KBD and the general population. The KBD detected rate of 3.39\% was expected based on a study conducted in Shaanxi Province in 2007 [22]. A sample size of 140 participants was estimated according to the following formula: $Z^{2}{ }_{a / 2} p(1-p) / d^{2}$ (where $a=0.05, Z_{a / 2}=1.96, p=0.0339, d=0.03$ ). This calculation is used to determine sample size in cross-sectional survey design [23], considering a sampling error of $3 \%$ and a confidence interval of $95 \%$. To decrease the missing data, we recruited 167 KBD patients. Therefore, 169 general subjects with joint pain in same area were used as a comparison group in the present study.

\section{KBD patients}

Patients with KBD were recruited from Shaanxi Province in China. At the time of screening, patients underwent a medical history evaluation, complete physical examination, and examination of the right hand radiographs. The clinical diagnosis of KBD was determined by at least two senior orthopedic surgeons from the local hospital according to the Diagnostic Criteria for KBD (WS/T207-2010).

\section{Inclusion and exclusion criteria}

Patients were included if they were diagnosed with KBD, were able to understand Mandarin, and had no cognitive impairment. Patients with concurrent rheumatoid arthritis, any other type of inflammatory arthritis, fibromyalgia, another chronic pain disorder or communication difficulties (e.g., hearing or speech impairments) were excluded. Ultimately, a total of 167 patients with KBD were recruited in this study.

\section{General population}

During the course of sampling, the subjects who did not meet the diagnostic criteria for KBD were compared as a control group to better understand the pain characteristics of patients with KBD. Three hundred twenty-five local residents with similar age and sex were recruited. Patients with communication difficulties (e.g., hearing or speech impairments) were excluded. Out of these 325 subjects, 169 answered yes to the question: "Are you generally bothered with joint pain?" Thus, 169 general participants were used as a comparison group in the present study.

\section{Measurements}

Patients with KBD and the general subjects completed a demographic questionnaire that obtained information on age, sex, ethnicity, marital status, occupation, and educational level.

\section{Pain characteristic assessment}

For both the KBD patients and the general subjects, pain was measured, including prevalence, duration, intensity, location, frequency, quality and method of treatment. The included subjects were asked to indicate whether they had pain. If they answered in the affirmative, we continued to ask about the sites, qualities (e.g., pins \& needles, swelling, burning, could-freezing, throbbing and itching), the frequency of pain in the last month, and pain duration from initial onset until now. In addition, participants were asked which pain treatments they used (i.e., analgesics, physical therapy or surgery).

\section{Pain sites}

Participants marked the site of pain using a body pain drawing, which is the most common method for assessing the site and distribution of joint pain [24]. The subjects were asked to shade areas where they had a specific side of pain (left/right/both) over the prior 6 months. The sites included the following joints: 1) knee, 2) ankle, 3) hip, 4) shoulder, 5) elbow, 6) wrist, 7) interphalangeal joints, and 8) toe. The number of joint pain sites was summed. In this study, the 
interphalangeal joint and toe joints were not easily counted; therefore, all painful interphalangeal joints were counted as one site of pain. In the analysis, we assessed a total of 16 joints. The number of joints affected in each patient ranged from 0 to 16 .

\section{Pain frequency}

Pain frequency (i.e., how often one experiences pain within a certain time frame) is an important component of the chronic pain experience [25]. The one-month period was recommended as a reliable recall period [26] and has been applied in various studies $[27,28]$. The frequency of joint pain in the last month was classified as "never," "some of the days," "about half of the days," "most of the days," or "every day"[29]. Persistent pain was defined as frequent (most days) or constant (every day) pain [30].

\section{Pain intensity}

Subjects were asked to provide separate intensity ratings for different pain sites. Pain intensity was measured on an 11-point numeric rating scale (NRS). The NRS is a one-dimensional pain assessment tool with scores ranging from 0 (no pain) to 10 (the worst pain imaginable), with higher scores indicating greater pain intensity. The NRS has been validated for use in the arthritis population [31].

\section{The graded chronic pain scale (GCPS)}

The GCPS is a multidimensional measure that assesses two dimensions of overall chronic pain severity during the past 6 months: pain intensity and pain-related disability. The GCPS consists of seven items. The pain intensity is calculated as the average of 3 questions concerning the present, worst, and average pain, as measured on a 0 to 10 scale, ranging from "no pain" to "pain as bad as could be". "Disability days" refers to the number of days for which pain prevented usual activities. The pain-related disability is calculated as the average of three questions on pain interference with daily activities, social and working activities; the three items are rated on an 11-point scale $(0=$ no interference/change, 10 = unable to carry on activities/extreme change). Scores on these two subscales range from 0 100 , where higher scores reflect greater pain intensity and disability. Pain severity was graded into 5 hierarchical categories: grades 0 to IV: Grade 0: no pain; Grade I, low disability-low intensity; Grade II, low disability-high intensity; Grade III, high disability-moderately limiting; and Grade IV, high disability-severely limiting. Because all the participants had pain in the current study, pain severity was graded into 4 hierarchical categories: grades I to IV. The GCPS is a valid and reliable instrument and suitable for use in all chronic pain conditions, including chronic musculoskeletal (MSK) pain [32]. The Chinese version of the GCPS possesses good psychometric properties, and the Cronbach a values for disability and characteristic intensity scales were 0.87 and 0.68 , respectively [33].

\section{The EuroQol (EQ-5D-3L) questionnaire}

The impact of pain is a key aspect to consider along with assessing the severity of pain [34]. The EuroQol (EQ-5D-3L) is a standardized preference-based measure of health that provides a simple, generic measure for clinical and economic assessment [35]. The participants were asked to complete the EQ-5D questionnaire (Chinese version). The EQ-5D records the level of self-reported problems in five dimensions (i.e., mobility, self-care, usual activities, pain/discomfort and anxiety/depression). Each of the dimensions is divided into three levels of perceived problems: no problem (level 1), some problems (level 2) and extreme problems (level 3). China EQ-5D-3L value sets were used in this study [36]. The scores on the EQ-5D index range from -0.149 to 1 , where 1 indicates no problem, zero indicates death and negative values indicate a health status worse than death. The EQ-5D-3L Chinese Version demonstrated fair to moderate levels of test-retest reliability and adequate construct validity in KBD individuals in China [37]. 


\section{Quality control}

Because nearly one-third of the subjects were illiterate, data were collected in face-to-face interviews by survey teams consisting of four Ph.D. students at the Department of Public Health at Xi'an Jiaotong University. All of the survey members had been trained in survey questionnaire procedures. Six staff members of the local Center for Disease Control and Prevention (CDC) helped us connect the included subjects, and our surveys were carried out at local community hospital. Completing the survey took approximately 20 to 25 minutes.

At the end of the survey, each participant received a thank you gift, such as a kitchen utensil. At the end of each day of interviews, all questionnaires were double-checked to check the quality of the questionnaires.

\section{Statistical analysis}

Continuous variables are presented as the mean \pm standard deviation, and categorical variables are presented as frequencies and proportions. The differences were evaluated using Chi-square tests, independent samples t-tests (for continuous variables), and Mann-Whitney U tests (for ordinal data); paired samples t-tests were used to determine differences between the left and right sides (within subjects) in joint pain intensity and 1-way ANOVA tests, or KruskalWallis tests were used for multiple group comparisons.

All data were analyzed using IBM SPSS Statistics for Windows, Version 22.0 (Armonk, NY: IBM Corp.). The level for significance in all analyses was defined as $\mathrm{P}<0.05$.

\section{Ethics}

All enrolled subjects were informed of the goal and design of this study and were assured of confidentiality before they provided written informed consent to participate in the study. The study was approved by the human ethics committee of the Health Science Center, Xi'an Jiaotong University.

\section{Results}

\section{Sample characteristics}

In all, 167 KBD patients and 169 general subjects were investigated in Shaanxi Province. All participants were Han Chinese. In the KBD group, nearly half of the patients were Grade I KBD (47.9\%), followed by grade II KBD (43.1\%), and Grade III KBD (9.0\%). No significant differences were found between the KBD and general groups in sex, age, education, marital status, or occupation. The demographic characteristics of the groups are listed in Table 1.

\section{Differences in pain site frequency and joint pain intensity in bilateral limbs of KBD patients}

Of the $167 \mathrm{KBD}$ patients recruited for this study, the most frequently reported painful joints for the bilateral sides were the knees (84.8\%), followed by ankles (79.2\%), wrists (51.2\%), shoulders (49.5\%) and elbows (47.7\%), while the hip (11.3\%) and toes (10.6\%) were the least frequently reported painful joints. As shown in Fig. 1, painful joints were symmetrically distributed between the right and left limbs; Pain intensities varied between 2.0 and 6.6 on the NRS for these pain sites. The most severe pain joint was the knee (NRS:6.6), followed by the ankles (NRS:5.1). The least painful joints were the hips (NRS:3.2) and the toes (NRS:2.0) (Fig. 2). There were no significant differences in pain frequency and mean pain intensity scores between the bilateral limb joints (both $\mathrm{p} \otimes 0.05$ ).

\section{Differences in the pain characteristics between the KBD and general groups}


In comparison to the general group, patients with KBD reported higher prevalence of joint pain (100\%) than controls $(52.0 \%, p<0.001)$, longer pain duration $(39.3 \pm 14.1)$ years for KBD patients $(8.9 \pm 6.9)$ than for general subjects $(p<$ $0.001)$, a significantly higher number of pain sites (7.2 \pm 3.8$)$ for KBD patients than for general subjects $(3.5 \pm 1.8, p<$ $0.001)$, higher pain frequency of persistent pain $(98.8 \%)$ for KBD patients than for general subjects $(50.9 \%, p<0.001)$, and a higher percentage of analgesics usage (89.2\%) than for general subjects $(30.7 \%, p<0.001)$. In the KBD group, the most commonly cited pain descriptors were pins \& needles (56.3\%), followed by aching, swelling, hot-burning and itching (53.9\%, 41.9\%, 36.5\% and $27.5 \%$, respectively). The most frequent sensation in the control group was "aching" $(46.7 \%)$, followed by pins \& needles (39.6\%). Except for aching pain, dull pain and background pain, the two groups differed in pain quality with respect to pins \& needles, swelling, burning, freezing and itching (all $p<0.05$ ), as shown in Table 1.

\section{Differences in GCPS pain intensity, pain disability, pain grade and EQ-5D scores between the KBD and general groups}

As shown in Tables 2 and 3, significant differences were seen between KBD patients and the general subjects in pain intensity, pain disability, pain grade distribution and EQ-5D scores (all p§0.001). Patients with KBD reported higher average, worst, and current pain scores, had higher pain disability scores with daily activities, social activities, and working ability, had a higher proportion of Grade $\otimes$ (high disability and severe limiting), and had worse health-related quality of life. Of note, Grade $\nabla$ was the most frequent pain grade (45.5\%), followed by Grade $\otimes(26.9 \%)$, Grade $\otimes$ $(22.2 \%)$, and Grade $\otimes(5.4 \%)$ in the KBD group. The distribution of pain grades in the general group was opposite to that of the KBD group, The two groups differed in the distribution of pain grade ( $\mathrm{p} \otimes 0.001)$.

\section{Factors associated with number of pain sites, pain frequency, GCPS pain intensity scores, pain disability scores, pain grade and EQ-5D scores in KBD subjects}

The factors that were associated with joint pain characteristics are shown in Table 4. Females and those with lower education level reported a higher number of total pain sites (both $\mathrm{p} \otimes 0.05$ ). Older participants reported a higher pain frequency and a longer pain duration (both $\mathrm{p} \varangle 0.05$ ). Regarding pain intensity scores, females and those with higher $\mathrm{KBD}$ grade reported higher pain intensity scores (both $\mathrm{p} \otimes 0.05$ ). Excepting age and marital status, participants who were

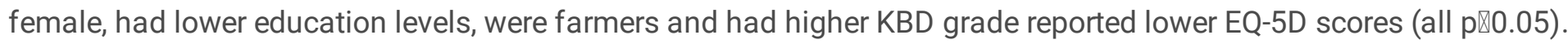
Nonetheless, no pain characteristic differences were observed in terms of marital status, and there were no differences in pain grade distribution across the sociodemographic variables (all pख0.05).

\section{Discussion}

In this study, we observed firstly the KBD subjects mainly manifested the more joint pain locations, worse pain intensity, higher pain frequency, longer pain duration, higher frequency of analgesia use, higher percentage of painrelated disability and lower quality of life, compared with the non-KBD control group. These findings suggest that KBD joint pain is a serious problem and that we should pay more attention to these vulnerable populations contrast to that of general subjects with pain.

To our knowledge, the main findings of KBD pain characteristics are as following: (1) KBD patients suffered from multisite, symmetrical and persistent joint pain, (2) weight-bearing joints (e.g., knees and ankles) were the most painful, (3) patients with KBD may experience neuropathic pain to varying degrees, (4) females with KBD were more likely to report a higher number of pain sites, pain intensity and lower quality of life than males, and (5) a high proportion of analgesic use (89.2\%) is the most important intervention to decrease the severity of pain. Taken together, these results indicate that joint pain of KBD is a significant and serious problem that requires more thorough understanding and treatment. 
Compared with previous studies, there are some differences with respect to the pain characteristics. First, the mean number of pain sites is lower than in a prior study conducted in the Aba area by Huang et al, who reported that the average number of affected joints for KBD patients was 8.8 [10]. One reason is that the count methods differed from our study; in Huang's study, he counted joint pain or/and enlargement joints ranging from 0 to 14, while in our study, we counted only painful joints ranging from 0 to 16 . Second, knees and ankles were the most severely and frequently affected joints in the current study. One explanation for this is that the knee and ankle move most frequently in daily life and are closely related to weight-bearing and/or working. However, this finding was somewhat different from a study conducted in Aba Tibetan area. In that study, the most severe site was the knee followed by the elbow[9]. The reasons for this discrepancy may be that the lifestyles are different in the two regions. Due to the high attitude environment, Tibetans often work in herding, while the people in Shaanxi Province often go into farming work (e.g., planting wheat and corn). Different working styles may mean that different body parts are used. The pain site may be different according to the body part used, degree of muscle activity, and working environment [38]. At present, many clinical trials of KBD pain interventions have focused on specific joint pain (e.g., knee pain) while routinely excluding individuals who report multiple pain issues[14, 39]. In the current study, other joints (e.g., fingers, elbows, shoulders) suffered mild pain, indicating that we should not pay attention to treatment of a specific joint pain. Future research should focus on the treatment of multiple cooccurring pain problems. Third, a higher proportion of analgesic use $(89.2 \%)$ is the most important intervention to decrease the severity of pain, suggesting that joint pain was bothersome and did not receive appropriate treatment. The reasons might be the lack of knowledge concerning causal mechanisms of pain in KBD and, therefore, the lack of effective treatment. In addition, the proportions of physical therapy and surgical procedures were both significantly low, although previous studies reported that the two methods were effective. [17-19]. One explanation for this finding may be that the KBD patients may not have the stamina to engage in physical therapy due to long-term treatment; the other is that the subjects may not be able to afford the cost of surgery due to financial reasons [40]. Therefore, future research needs to develop various pharmacologic and nonpharmacologic interventions to manage pain in KBD patients.

Some researchers have viewed KBD as a special kind of osteoarthritis (OA) due to the similar characteristics [7]; however, there are differences between OA pain and KBD pain. for instance, $98 \%$ of the KBD subjects reported persistent pain, a finding that differed from that of OA. One study identified two distinct types of OA pain: one that was intermittent but generally severe or intense, and a more persistent 'background' pain or aching [41]. Therefore, we should consider the treatments of KBD pain based on its own pain characteristics.

Pain is currently categorized into nociceptive (often inflammatory) pain resulting from tissue damage; neuropathic pain, involving nerve damage; and idiopathic pain, which has no identified cause [42]. Because neuropathic pain is treated differently from other types of pain [43], recognizing neuropathic pain is important. Due to damage to joint cartilage[10], the joint pain reported in KBD patients is referred to as "nociceptive pain". However, many KBD participants in our study used pain descriptors that might typically be associated with a neuropathic pain process, such as pins \& needles and burning. These findings suggest that patients with KBD may experience joint pain caused by both nociceptive and neuropathic mechanisms to varying degrees. Further research is warranted to examine the role of neuropathic pain in KBD and the relationship between nociceptive pain and neuropathic pain.

Literature regarding the associations between pain characteristics and demographics had not been investigated in detail. In the current study, women were more likely to report a higher number of pain sites, higher pain intensity and lower quality of life. These findings are consistent with prior studies on musculoskeletal pain $[44,45]$. Additionally, the higher the grade of KBD is, the higher pain intensity and the lower quality of life are, suggesting that we could implement the Policy of Poverty Alleviation on KBD subjects according to KBD grade. A previous study found that age was related to KBD pain scores [9]. Nevertheless, in this study, we did not find an association between age and pain 
intensity scores. A possible explanation for this observation is that the majority of samples in our study were older than 50 years of age, whereas the KBD patients in that study were younger than 50 years of age; older individuals may have learned to modify their work habits to avoid pain more than younger individuals [46].

\section{Limitations}

There were several limitations in this study. First, we may have overlooked the pain characteristics associated with the early stages of KBD due to a lack of new KBD cases. Second, many subjects were currently using analgesia or antiinflammatory drugs, which may have resulted in conservative estimates of joint pain intensity. Third, we did not investigate the psychological dimension related to pain characteristics, as the majority of the participants were older than 50 years of age, and they became impatient due to the long time required for the survey. Future study is needed to survey the psychological factors related to pain characteristics.

\section{Conclusion}

In summary, this is the first study of joint pain characteristics of KBD patients. This study found that KBD patients reported more joint pain sites, worse pain intensity, higher pain frequency, longer pain duration, higher frequency of analgesia use, higher proportions of disability and lower quality of life than those in the control group. In the KBD group, the majority of the patients experienced multiple, symmetrical, persistent, and neuropathic pain; weight-bearing joints (e.g., knee and ankle) were the most painful. Furthermore, females were more likely report higher numbers of pain sites, higher pain intensity and lower quality of life. These findings will provide scientific basis for establishing joint pain evaluation criteria and subsequent pain intervention for KBD patients in China.

\section{Abbreviations}

KBD: Kashin-Beck disease; VAS: Visual Analog Scale; OA: Osteoarthritis; IAHA: Intra-articular injections of Hyaluronic Acid; NRS: Numeric Rating Scale; GCPS: The Graded Chronic Pain Scale; EQ-5D-3L: The EuroQol five-dimensional questionnaire three-level; CDC: Center for Disease Control

\section{Declarations}

\section{Acknowledgements}

We thank the staff of the local township hospitals and the County Endemic Disease Control Center of Linyou and Yongshou County for their support in contacting the subjects included in this study.

\section{Authors' contributors}

All authors were involved in drafting the article or revising it critically for important intellectual content, and all authors approved the final version to be published. Wang Dimiao had full access to all of the data in the study and takes responsibility for the integrity of the data and the accuracy of the data analysis. Study design: Wang Dimiao, Mohammad Imran Younus, Hua Fang, Guo Xiong. Acquisition of data: Wang Dimiao, Chao Xu, Fang Hua, Liu Huan, Mohammad Imran Younus. Analysis and interpretation of the data: Wang Dimiao, Hua Fang. Writing: Wang Dimiao, Mohammad Imran Younus. Statistical analysis: Wang Dimiao, Mohammad Imran Younus.

\section{Funding}


This research was supported by the National Natural Science Foundation of China (81620108026 and 81302393) and the Nursing Young Teacher Research Fund of China Medical Board (CMB) (13-168-201409).

\section{Ethics approval and consent to participate}

The study was approved by the human ethics committee of the Health Science Center, Xi'an Jiaotong University, and all subjects provided written informed consent.

\section{Consent for publication}

Not applicable.

\section{Competing interests}

The authors declare that they have no competing interests.

\section{Authors details}

${ }^{1}$ School of Nursing, Health Science Center of Xi'an Jiaotong University, Xi'an, P.R. China. ${ }^{2}$ Deputy District Officer Health Taxila, District Rawalpindi, Pakistan. ${ }^{3}$ Linyou Hospital of Traditional Chinese Medicine, Shaanxi Province, P.R. China. ${ }^{4}$ School of Public Health, Health Science Center of Xi'an Jiaotong University, NHC Key Laboratory of Trace Elements and Endemic Diseases (Xi'an Jiaotong University), Xi'an, P.R. China. Collaborative Innovation Center of Endemic Diseases and Health Promotion in the Silk Road Region (Xi'an Jiaotong University), Xi'an, P.R. China.

*Address correspondence and reprint requests to: Xiong Guo, School of Public Health, Xi'an Jiaotong University Health Science Center, Xi'an, Shaanxi 710061, P.R. China. Fax: 86-02982655091. ORCID:0000-0003-4413-5022

\section{References}

1. Xiong G. Diagnostic, clinical and radiological characteristics of Kashin-Beck disease in Shaanxi Province, PR China. International Orthopaedics 2001; 25(3):147-50.

2. Guo X, Ma WJ, Zhang F, Ren FL, Qu CJ, Lammi MJ. Recent advances in the research of an endemic osteochondropathy in China: Kashin-Beck disease. Osteoarthritis and cartilage / OARS, Osteoarthritis Research Society 2014; 22(11):1774-83.

3. Ning Y, Wang X, Zhang P, Anatoly SV, Prakash NT, Li C, et al. Imbalance of dietary nutrients and the associated differentially expressed genes and pathways may play important roles in juvenile Kashin-Beck disease. J Trace Elem Med Biol 2018; 50:441-60.

4. Yu FF, Ping ZG, Yao C, Wang ZW, Wang FQ, Guo X. Evaluation of the Sensitivity and Specificity of the New Clinical Diagnostic and Classification Criteria for Kashin-Beck Disease, an Endemic Osteoarthritis, in China. Biomed Environ Sci 2017; 30(2):150-5.

5. Luo R, Liu G, Liu W, Pei F, Zhou Z, Li J, et al. Efficacy of celecoxib, meloxicam and paracetamol in elderly KashinBeck disease (KBD) patients. Int Orthop 2011; 35(9):1409-14.

6. Wang K, Yu J, Liu H, Liu Y, Liu N, Cao Y, et al. Endemic Kashin-Beck disease: A food-sourced osteoarthropathy. Seminars in Arthritis and Rheumatism 2020; 50(2):366-72.

7. Cao J, Li S, Shi Z, Yue Y, Sun J, Chen J, et al. Articular cartilage metabolism in patients with Kashin-Beck Disease: an endemic osteoarthropathy in China. Osteoarthritis and cartilage / OARS, Osteoarthritis Research Society 2008; 16(6):680-8. 
8. Blyth FM, Noguchi N. Chronic musculoskeletal pain and its impact on older people. Best practice \& research Clinical rheumatology 2017; 31(2):160-8.

9. Li Y, Zhou Z, Shen B, Yang J, Kang P, Yang X, et al. Clinical features of Kashin-Beck disease in adults younger than 50 years of age during a low incidence period: severe elbow and knee lesions. Clin Rheumatol 2013; 32(3):317-24.

10. Huang Q, Zhou ZK, Ma J, Li Y, Yang X, Shen B, et al. The arthropathic and functional impairment features of adult Kashin-Beck disease patients in Aba Tibetan area in China. Osteoarthritis and cartilage / OARS, Osteoarthritis Research Society 2015; 23(4):601-6.

11. Cao CX, Zhang YG, Wu SX, Younas MI, Guo X. Association of clinical features of bone and joint lesions between children and parents with Kashin-Beck disease in Northwest China. Clin Rheumatol 2013; 32(9):1309-16.

12. F. Mathieu FB, Zhang Yong Lan, C. Suetens,M. Hinsenkamp. Clinical manifestations of Kashin-Beck disease in Nyemo Valley. International Orthopaedics 1997; 21:151-56.

13. Jensen MP, Johnson LE, Gertz KJ, Galer BS, Gammaitoni AR. The words patients use to describe chronic pain: implications for measuring pain quality. Pain 2013; 154(12):2722-8.

14. Tang X, Zhou ZK, Liu G, Shen B, Kang PD, Li J, et al. The long-term efficacy and tolerability of hyaluronic acid in adult patients with Kashin-Beck disease of the knee. Clin Rheumatol 2015; 34(1):151-6.

15. Liu W, Liu G, Pei F, Liu Y, Zhou Z, Li J, et al. Kashin-Beck disease in Sichuan, China: report of a pilot open therapeutic trial. Journal of clinical rheumatology : practical reports on rheumatic \& musculoskeletal diseases 2012; 18(1):8-14.

16. Dongmei. X, Ronghai. w, Yulin. L, Li. X, Jirong. Y, Chuanyao. D. Selenium Supplementation for Treatment of Kashin-Beck Disease: A Network Meta-analysis. Chinese Journal of Evidence-Based Medicine 2016; 16(11):128490.

17. Tang X, Zhou ZK, Shen B, Kang PD, Yang J, Li J, et al. Total knee arthroplasty in elderly patients with severe Kashin-Beck disease of the knee. Int Orthop 2014; 38(4):753-9.

18. Tang X, Zhu J, Zhou Z, Shen B, Kang P, Pei F, et al. Total hip replacement in adult patients with severe Kashin-Beck disease of the hip. BMC Musculoskelet Disord 2016; 17:289.

19. Mathieu F, Suetens C, Begaux F, De Maertelaer V, Hinsenkamp M. Effects of physical therapy on patients with Kashin-Beck disease in Tibet. International Orthopaedics 2001; 25(3):191-3.

20. Xufeng. Z, Yunqi. I, Jun. Y. summary for experience and process of prevention and control of Kashin-Beck disease in China(In Chinese). Chin J Endemiol 2019; 38(8):603-6.

21. Diagnosis of Kashin-Beck disease (WS/T207-2010). National Health Commission of the people's Republic of China; 2020;:Available from:http://www.nhc.gov.cn/wjw/s9500/201006/47920.shtml. Accessed 20 Aug 2020.

22. Yunqi. L, Hui. I, Lijun. Z, Ben. G. Development of the eliminating standard for Kaschin-Beck disease in China(In Chinese). Chin J Endemiol 2011; 30:14-22.

23. Si H, Wang C, Jin Y, Tian X, Qiao X, Liu N, et al. Prevalence, Factors, and Health Impacts of Chronic Pain Among Community-Dwelling Older Adults in China. Pain Manag Nurs 2019; 20(4):365-72.

24. Fillingim RB, Loeser JD, Baron R, Edwards RR. Assessment of Chronic Pain: Domains, Methods, and Mechanisms. The Journal of Pain 2016; 17(9):T10-T20.

25. Robinson KT, Bergeron CD, Mingo CA, Meng L, Ahn S, Towne SD, Jr., et al. Factors Associated With Pain Frequency Among Adults With Chronic Conditions. J Pain Symptom Manage 2017; 54(5):619-27.

26. Jeffries L, Milanese S, Grimmer-Somers K. Epidemiology of adolescent spinal pain: a systematic overview of the research literature. Spine J 2007; 32(23):2630-7. 
27. Pellise F, Balague F, Rajmil L, Cedraschi C, Aguirre M, Fontecha CG ea. Prevalence of low back pain and its effect on health-related quality of life in adolescents. Arch Pediatr Adolesc Med 2009;; 163(1):65-71.

28. DWatsonab. K, CPapageorgioua. A, TJonesab. G, StewartTaylora., P.MSymmonsa. D, JSilmana. A, et al. Low back pain in schoolchildren: occurrence and characteristics Pain 2002; 97(1-2):87-92.

29. dela Cruz AM, Bernstein IH, Greer TL, Walker R, Rethorst CD, Grannemann B, et al. Self-rated measure of pain frequency, intensity, and burden: psychometric properties of a new instrument for the assessment of pain. $J$ Psychiatr Res 2014; 59:155-60.

30. Kennedy J, Roll JM, Schraudner T, Murphy S, McPherson S. Prevalence of persistent pain in the U.S. adult population: new data from the 2010 national health interview survey. The journal of pain : official journal of the American Pain Society 2014; 15(10):979-84.

31. Hawker GA, Mian S, Kendzerska T, French M. Measures of adult pain: Visual Analog Scale for Pain (VAS Pain), Numeric Rating Scale for Pain (NRS Pain), McGill Pain Questionnaire (MPQ), Short-Form McGill Pain Questionnaire (SF-MPQ), Chronic Pain Grade Scale (CPGS), Short Form-36 Bodily Pain Scale (SF-36 BPS), and Measure of Intermittent and Constant Osteoarthritis Pain (ICOAP). Arthritis Care Res (Hoboken) 2011; 63 Suppl $11: S 240-52$

32. Von Korff M, Ormel J, Keefe FJ, Dworkin SF. Grading the severity of chronic pain. Pain 1992; 50(2):133-49.

33. Wong WS, Jensen MP, Mak KH, Tam BK, Fielding R. Preliminary psychometric properties of the Chinese version of the Chronic Pain Coping Inventory (ChCPCl) in a Hong Kong Chinese population. The journal of pain : official journal of the American Pain Society 2010; 11(7):672-80.

34. Herr K. Pain assessment strategies in older patients. The journal of pain : official journal of the American Pain Society 2011; 12 (3 Suppl 1):S3-S13.

35. Golicki D, Niewada M, Karlinska A, Buczek J, Kobayashi A, Janssen MF, et al. Comparing responsiveness of the EQ-5D-5L, EQ-5D-3L and EQ VAS in stroke patients. Quality of life research : an international journal of quality of life aspects of treatment, care and rehabilitation 2015; 24(6):1555-63.

36. Liu GG, Wu H, Li M, Gao C, Luo N. Chinese time trade-off values for EQ-5D health states. Value Health 2014; 17(5):597-604.

37. Fang H, Farooq U, Wang D, Yu F, Younus MI, Guo X. Reliability and validity of the EQ-5D-3L for Kashin-Beck disease in China. Springerplus 2016; 5(1):1924.

38. Chris Jensen, Vilhelm Borg, MA LoF, Klaus Hansen, Juul-Kristen $\otimes B$, Hanne Christensen. Job demands, muscle activity and musculoskeletal symptoms in relation to work with the computer mouse. Scand J Work Environ Health 1998; 24(5):418-24.

39. Tang X, Pei FX, Zhou ZK, Liu G, Shen B, Kang PD, et al. A randomized, single-blind comparison of the efficacy and tolerability of hyaluronate acid and meloxicam in adult patients with Kashin-Beck disease of the knee. Clin Rheumatol 2012; 31(7):1079-86.

40. Xiong G. New progression and prospect on pathogenesis and control of Kashin-Beck disease(in Chinese). Forign Medical Science Section of Medgeography 2010; 31(1):1-4.

41. Hawker GA, Stewart L, French MR, Cibere J, Jordan JM, March L, et al. Understanding the pain experience in hip and knee osteoarthritis-an OARSI/OMERACT initiative. Osteoarthritis and cartilage / OARS, Osteoarthritis Research Society 2008; 16(4):415-22.

42. Thakur M, Dickenson AH, Baron R. Osteoarthritis pain: nociceptive or neuropathic? Nat Rev Rheumatol 2014; 10(6):374-80. 
43. Attal N, Bouhassira D, Baron R. Diagnosis and assessment of neuropathic pain through questionnaires. The Lancet Neurology 2018; 17(5):456-66.

44. Elboim-Gabyzon M, Rozen N, Laufer Y. Gender differences in pain perception and functional ability in subjects with knee osteoarthritis. ISRN orthopedics 2012; 2012:413105.

45. Wijnhoven $\mathrm{HAH}$, de Vet HCW, Picavet HSJ. Prevalence of musculoskeletal disorders is systematically higher in women than in men. The Clinical Journal of Pain 2006; 22(8):717-24.

46. Min D, Baek S, Park HW, Lee SA, Moon J, Yang JE, et al. Prevalence and Characteristics of Musculoskeletal Pain in Korean Farmers. Ann Rehabil Med 2016; 40(1):1-13.

\section{Tables}

Table 1 Differences in demographics and pain characteristics between the KBD group and the general group 


\begin{tabular}{|c|c|c|c|}
\hline Characteristics & $\begin{array}{l}\text { KBD group } \\
(n=167)\end{array}$ & $\begin{array}{l}\text { General group } \\
(n=169)\end{array}$ & $p$ value \\
\hline \multicolumn{4}{|l|}{ Sex, n (\%) } \\
\hline Male & $84(50.3)$ & $72(42.6)$ & 0.157 \\
\hline Female & $83(49.7)$ & $97(57.4)$ & \\
\hline Age in years, mean $\pm S D$ (min-max) & $58.4 \pm 10.2(40-83)$ & $\begin{array}{l}58.7 \pm 8.1(40- \\
81)\end{array}$ & 0.721 \\
\hline \multicolumn{4}{|l|}{ Education, n (\%) } \\
\hline Illiterate & $49(29.3)$ & $46(27.2)$ & 0.272 \\
\hline Primary school & $51(30.5)$ & $49(28.9)$ & \\
\hline Middle school & $55(32.9)$ & $49(28.9)$ & \\
\hline 2High school & $12(7.2)$ & $25(14.8)$ & \\
\hline \multicolumn{4}{|l|}{ Marital status, n (\%) } \\
\hline Single & $18(10.8)$ & $11(6.5)$ & 0.163 \\
\hline Married & $149(89.2)$ & $158(93.5)$ & \\
\hline \multicolumn{4}{|l|}{ Occupation, n (\%) } \\
\hline Farmer & $158(94.6)$ & $165(97.6)$ & 0.151 \\
\hline Others & $9(5.4)$ & $4(2.4)$ & \\
\hline \multicolumn{4}{|l|}{ Grade of disease, $n(\%)$} \\
\hline Grade I & $80(47.9)$ & I & \\
\hline Grade $\otimes$ & $72(43.1)$ & / & \\
\hline Grade $\otimes$ & $15(9.0)$ & / & \\
\hline Pain prevalence, $n$ (\%) & $167(100.0)$ & $169(52.0)$ & 00.001 \\
\hline Pain duration (years), mean $\pm S D$ (min-max) & $39.3 \pm 14.1(25-59)$ & $8.9 \pm 6.9(1-30)$ & $\square 0.001$ \\
\hline Number of total pain sites, mean $\pm S D$ (min-max) & $7.2 \pm 3.8(1-16)$ & $3.5 \pm 1.8(0-4)$ & 00.001 \\
\hline $\begin{array}{l}\text { Number of pain sites in the upper limbs, mean } \pm S D \text { (min- } \\
\text { max) }\end{array}$ & $3.4 \pm 2.5(0-8)$ & $1.3 \pm 1.2(0-4)$ & 00.001 \\
\hline $\begin{array}{l}\text { Number of pain sites in the lower limbs, mean } \pm \text { SD (min- } \\
\text { max) }\end{array}$ & $3.8 \pm 1.7(1-8)$ & $2.2 \pm 1.2(0-4)$ & 00.001 \\
\hline \multicolumn{4}{|l|}{ Number of pain sites , $\mathrm{n}(\%)$} \\
\hline 1 & $5(2.7)$ & $21(12.2)$ & 00.001 \\
\hline 2-6 & $38(23.0)$ & $103(61.0)$ & \\
\hline 7-11 & $54(32.4)$ & $45(26.8)$ & \\
\hline $12-16$ & 70 (41.9) & $0(0)$ & \\
\hline
\end{tabular}




\begin{tabular}{|c|c|c|c|}
\hline \multicolumn{4}{|c|}{ Frequency of pain in the last month, $\mathrm{n}(\%)$} \\
\hline Never & $0(0.0)$ & $0(0.0)$ & $\square 0.001$ \\
\hline Some of the days & $0(0.0)$ & $24(14.2)$ & \\
\hline About half of the days & $2(1.2)$ & $59(34.9)$ & \\
\hline Most of the days & $53(31.7)$ & $41(24.3)$ & \\
\hline Every day & $112(67.1)$ & $45(26.6)$ & \\
\hline \multicolumn{4}{|l|}{ Pain quality, n (\%) } \\
\hline Pins \& needles & $94(56.3)$ & $67(39.6)$ & 0.002 \\
\hline Aching pain & $90(53.9)$ & $79(46.7)$ & 0.190 \\
\hline Swelling pain & $70(41.9)$ & $26(15.4)$ & 00.001 \\
\hline Hot-burning pain & $61(36.5)$ & $12(7.1)$ & [0.001 \\
\hline Itching & $46(27.5)$ & $2(1.2)$ & 00.001 \\
\hline Cold-freezing pain & $30(17.9)$ & $12(7.1)$ & 0.003 \\
\hline Dull pain & $17(10.2)$ & $8(4.7)$ & 0.057 \\
\hline Background pain & $13(7.8)$ & $10(5.9)$ & 0.498 \\
\hline \multicolumn{4}{|l|}{ Pain treatment, n (\%) } \\
\hline Analgesics & $149(89.2)$ & $52(30.7)$ & $\square 0.001$ \\
\hline Physical therapy & $58(34.7)$ & $66(39.1)$ & 0.430 \\
\hline Surgical procedures & $3(1.8)$ & $1(0.6)$ & 0.370 \\
\hline
\end{tabular}

Table 2 Differences in GCPS between the KBD group and the general group 


\begin{tabular}{|c|c|c|c|}
\hline Items & KBD group ( $n=167)$ & $\begin{array}{l}\text { General group } \\
(n=169)\end{array}$ & $\begin{array}{l}p \\
\text { value }\end{array}$ \\
\hline \multicolumn{4}{|l|}{ Pain intensity } \\
\hline Current pain intensity, mean \pm SD (min-max) & $7.2 \pm 1.8(2-10)$ & $4.4 \pm 2.0(0-9)$ & $\square 0.001$ \\
\hline Worst pain intensity, mean $\pm S D$ (min-max) & $8.1 \pm 1.9(3-10)$ & $6.0 \pm 2.7(1-10)$ & $\square 0.001$ \\
\hline Average pain intensity, mean $\pm S D$ (min-max) & $6.8 \pm 1.6(3-10)$ & $4.6 \pm 2.0(1-10)$ & $\square 0.001$ \\
\hline \multicolumn{4}{|l|}{ Disability days, n (\%) } \\
\hline $0-6$ & $48(28.7)$ & $134(79.3)$ & $\square 0.001$ \\
\hline $7-14$ & $20(12.0)$ & $16(9.5)$ & \\
\hline $15-30$ & $33(19.8)$ & $19(11.2)$ & \\
\hline$\varangle \mathbf{3 0}$ & $66(39.5)$ & $0(0.0)$ & \\
\hline \multicolumn{4}{|l|}{ Pain interference } \\
\hline Daily activities, mean \pm SD (min-max) & $6.2 \pm 2.3(0-10)$ & $4.1 \pm 2.5(0-10)$ & $\square 0.001$ \\
\hline Social activities, mean \pm SD (min-max) & $5.6 \pm 2.6(0-10)$ & $3.8 \pm 2.5(0-10)$ & प0.001 \\
\hline Working ability, mean $\pm S D$ (min-max) & $6.5 \pm 2.7(0-10)$ & $4.7 \pm 2.7(0-10)$ & $\square 0.001$ \\
\hline $\begin{array}{l}\text { GCPS total pain intensity, mean } \pm S D \text { (min- } \\
\max \text { ) }\end{array}$ & $\begin{array}{l}73.8 \pm 15.2(30.0- \\
100.0)\end{array}$ & $\begin{array}{l}50.0 \pm 20.7(10.0- \\
90.3)\end{array}$ & $\square 0.001$ \\
\hline $\begin{array}{l}\text { GCPSpain-related disability, mean } \pm \text { SD (min- } \\
\text { max) }\end{array}$ & $61.2 \pm 23.3(0-100)$ & $41.6 \pm 23.2(0-100)$ & $\square 0.001$ \\
\hline \multicolumn{4}{|l|}{ Pain grade, $\mathrm{n}(\%)$} \\
\hline$\square$ & $9(5.4)$ & $75(44.4)$ & $\square 0.001$ \\
\hline ૫ & 37 (22.2) & $52(30.8)$ & \\
\hline$\square$ & 45 (26.9) & $34(20.1)$ & \\
\hline$\square$ & $76(45.5)$ & $8(4.7)$ & \\
\hline
\end{tabular}

Table 3 Differences in EQ-5D between the KBD group and the general group 


\begin{tabular}{|c|c|c|c|c|c|c|c|}
\hline \multirow[t]{2}{*}{ EQ-5D items } & \multicolumn{3}{|c|}{ KBD group $(n=167)$} & \multicolumn{3}{|c|}{ General group $(n=169)$} & \multirow{2}{*}{$\begin{array}{l}p \\
\text { value }\end{array}$} \\
\hline & $\begin{array}{l}\text { No } \\
\text { problem }\end{array}$ & $\begin{array}{l}\text { Some } \\
\text { problems }\end{array}$ & $\begin{array}{l}\text { Extreme } \\
\text { problems }\end{array}$ & $\begin{array}{l}\text { No } \\
\text { problem }\end{array}$ & $\begin{array}{l}\text { Some } \\
\text { problems }\end{array}$ & $\begin{array}{l}\text { Extreme } \\
\text { problems }\end{array}$ & \\
\hline Mobility, n (\%) & $\begin{array}{l}26 \\
(15.6)\end{array}$ & $90(53.9)$ & $51(30.5)$ & $\begin{array}{l}55 \\
(32.5)\end{array}$ & $\begin{array}{l}100 \\
(59.2)\end{array}$ & $14(8.3)$ & $\square 0.001$ \\
\hline Self-care, n (\%) & $\begin{array}{l}35 \\
(21.0)\end{array}$ & $102(61.1)$ & $30(17.9)$ & $\begin{array}{l}126 \\
(74.6)\end{array}$ & $37(21.9)$ & $6(3.5)$ & \multirow{2}{*}{$\begin{array}{l}{[0.001} \\
\square 0.001\end{array}$} \\
\hline $\begin{array}{l}\text { Usual activities, } n \\
(\%)\end{array}$ & $11(6.6)$ & $123(73.7)$ & $33(19.8)$ & $\begin{array}{l}61 \\
(36.1)\end{array}$ & $\begin{array}{l}106 \\
(62.7)\end{array}$ & $2(1.2)$ & \\
\hline $\begin{array}{l}\text { Pain/discomfort, } n \\
\text { (\%) }\end{array}$ & $0(0)$ & $95(56.9)$ & $72(43.1)$ & $0(0)$ & $\begin{array}{l}153 \\
(90.5)\end{array}$ & $16(9.5)$ & $\square 0.001$ \\
\hline $\begin{array}{l}\text { Anxiety/depression, } \\
\text { n (\%) }\end{array}$ & $\begin{array}{l}32 \\
(19.2)\end{array}$ & $103(61.7)$ & $32(19.2)$ & $\begin{array}{l}59 \\
(34.9)\end{array}$ & $\begin{array}{l}110 \\
(65.1)\end{array}$ & $0(0)$ & 00.001 \\
\hline $\begin{array}{l}\text { EQ-5D index scores, } \\
(\text { mean } \pm S D)\end{array}$ & \multicolumn{3}{|l|}{$0.34 \pm 0.27$} & \multicolumn{3}{|l|}{$0.59 \pm 0.16$} & $\square 0.001$ \\
\hline
\end{tabular}

Table 4 Differences of pain characteristics and EQ-5D index scores among demographic characteristics in the KBD group 


\begin{tabular}{|c|c|c|c|c|c|c|c|c|c|}
\hline \multirow[t]{2}{*}{ Items } & \multirow{2}{*}{$\begin{array}{l}\text { Pain duration } \\
\text { (years),(mean } \\
\pm \text { SD) }\end{array}$} & \multicolumn{3}{|c|}{$\begin{array}{l}\text { Number of pain sites,(mean } \pm \\
\text { SD) }\end{array}$} & \multicolumn{5}{|c|}{ Pain frequency in one month, (n) } \\
\hline & & Total & $\begin{array}{l}\text { Upper } \\
\text { limb }\end{array}$ & $\begin{array}{l}\text { Lower } \\
\text { limb }\end{array}$ & Never & $\begin{array}{l}\text { Some } \\
\text { of the } \\
\text { days }\end{array}$ & $\begin{array}{l}\text { About } \\
\text { half } \\
\text { of the } \\
\text { days }\end{array}$ & $\begin{array}{l}\text { Most } \\
\text { of } \\
\text { the } \\
\text { days }\end{array}$ & $\begin{array}{l}\text { Every } \\
\text { day }\end{array}$ \\
\hline \multicolumn{10}{|l|}{ Sex } \\
\hline $\begin{array}{l}\text { Male } \\
(n=84)\end{array}$ & $40.6 \pm 14.6$ & $5.9 \pm 3.1 *$ & $2.7 \pm 2.2^{*}$ & $3.1 \pm 1.4^{*}$ & 0 & 0 & 1 & 27 & 56 \\
\hline $\begin{array}{l}\text { Female } \\
(\mathrm{n}=83)\end{array}$ & $38.0 \pm 13.8$ & $7.9 \pm 3.2$ & $4.0 \pm 2.6$ & $4.1 \pm 1.8$ & 0 & 0 & 1 & 26 & 56 \\
\hline \multicolumn{10}{|c|}{ Age range } \\
\hline $\begin{array}{l}40-49 \\
(n=10)\end{array}$ & $33.8 \pm 5.7^{\star}$ & $8.0 \pm 3.5$ & $3.3 \pm 2.3$ & $4.7 \pm 1.1$ & 0 & 0 & 0 & 4 & $6 * *$ \\
\hline $\begin{array}{l}50-59 \\
(n=71)\end{array}$ & $35.2 \pm 12.8$ & $7.0 \pm 4.1$ & $3.1 \pm 2.7$ & $3.9 \pm 1.9$ & 0 & 0 & 1 & 22 & 48 \\
\hline $\begin{array}{l}60-69 \\
(n=74)\end{array}$ & $41.8 \pm 14.4$ & $7.5 \pm 3.7$ & $2.7 \pm 2.5$ & $3.8 \pm 1.6$ & 0 & 0 & 1 & 23 & 50 \\
\hline $\begin{array}{l}\geq 70 \\
(n=12)\end{array}$ & $54.2 \pm 12.9$ & $5.5 \pm 2.8$ & $2.5 \pm 2.1$ & $3.1 \pm 1.3$ & 0 & 0 & 0 & 4 & 8 \\
\hline \multicolumn{10}{|c|}{ Education } \\
\hline $\begin{array}{l}\text { Illiterate } \\
(\mathrm{n}=49)\end{array}$ & $38.9 \pm 14.1$ & $7.6 \pm 3.3^{\star}$ & $3.5 \pm 2.4$ & $4.1 \pm 1.5^{*}$ & 0 & 0 & 0 & 16 & 33 \\
\hline $\begin{array}{l}\text { Primary } \\
\text { school } \\
(n=51)\end{array}$ & $38.4 \pm 14.3$ & $6.7 \pm 4.0$ & $3.1 \pm 2.5$ & $3.7 \pm 1.8$ & 0 & 0 & 1 & 13 & 37 \\
\hline $\begin{array}{l}\text { Middle } \\
\text { school } \\
(n=55)\end{array}$ & $39.9 \pm 14.9$ & $6.4 \pm 3.4$ & $2.9 \pm 2.4$ & $3.5 \pm 1.5$ & 0 & 0 & 1 & 19 & 35 \\
\hline $\begin{array}{l}\text { ZHigh } \\
\text { school } \\
(n=12)\end{array}$ & $42.0 \pm 12.5$ & $4.3 \pm 3.6$ & $1.5 \pm 2.3$ & $2.8 \pm 1.6$ & 0 & 0 & 0 & 5 & 7 \\
\hline \multicolumn{10}{|l|}{$\begin{array}{l}\text { Marital } \\
\text { status }\end{array}$} \\
\hline $\begin{array}{l}\text { Single } \\
(n=18)\end{array}$ & $39.1 \pm 15.9$ & $6.0 \pm 3.1$ & $3.2 \pm 2.6$ & $3.0 \pm 1.1$ & 0 & 0 & 0 & 7 & 11 \\
\hline $\begin{array}{l}\text { Married } \\
(n=149)\end{array}$ & $39.3 \pm 14.2$ & $7.3 \pm 3.8$ & $3.4 \pm 2.5$ & $3.8 \pm 1.6$ & 0 & 0 & 2 & 46 & 101 \\
\hline \multicolumn{10}{|c|}{ Occupation } \\
\hline $\begin{array}{l}\text { Farmer } \\
(\mathrm{n}=158)\end{array}$ & $39.1 \pm 14.4$ & $7.6 \pm 3.7$ & $3.5 \pm 2.4$ & $3.9 \pm 1.7$ & 0 & 0 & 2 & 50 & 106 \\
\hline $\begin{array}{l}\text { Others } \\
(n=9)\end{array}$ & $42.8 \pm 10.7$ & $6.9 \pm 4.2$ & $3.0 \pm 2.5$ & $3.9 \pm 1.3$ & 0 & 0 & 0 & 3 & 6 \\
\hline
\end{tabular}




\begin{tabular}{|c|c|c|c|c|c|c|c|c|c|}
\hline $\begin{array}{l}\text { Grade I } \\
(n=80)\end{array}$ & $39.8 \pm 13.7$ & $8.4 \pm 4.1$ & $4.1 \pm 2.7$ & $4.4 \pm 1.8$ & 0 & 0 & 1 & 25 & 54 \\
\hline 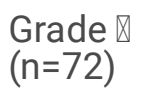 & $37.3 \pm 15.1$ & $6.3 \pm 3.0$ & $3.0 \pm 2.1$ & $3.4 \pm 1.4$ & 0 & 0 & 1 & 23 & 48 \\
\hline $\begin{array}{l}\text { Grade } \otimes \\
(n=15)\end{array}$ & $45.0 \pm 9.6$ & $6.3 \pm 3.8$ & $3.1 \pm 2.8$ & $3.1 \pm 1.7$ & 0 & 0 & 0 & 5 & 10 \\
\hline
\end{tabular}

${ }^{*} p$ value $<0.05,{ }^{* *} p$ value $<0.01$

Table 4 Continued: Differences of pain characteristics and EQ-5D index scores among demographic characteristics in the KBD group 


\begin{tabular}{|c|c|c|c|c|c|c|c|}
\hline \multirow[t]{2}{*}{ Items } & \multirow{2}{*}{$\begin{array}{l}\text { GCPS pain intensity, } \\
\text { (mean } \pm \text { SD) }\end{array}$} & \multirow{2}{*}{$\begin{array}{l}\text { GCPS pain disability, } \\
\text { (mean } \pm \text { SD) }\end{array}$} & \multirow{2}{*}{$\begin{array}{l}\text { EQ-5D, } \\
\text { (mean } \pm \text { SD) }\end{array}$} & \multicolumn{4}{|c|}{ GCPS pain grade $(n)$} \\
\hline & & & & प & प & प & $\square$ \\
\hline \multicolumn{8}{|l|}{ Sex } \\
\hline Male $(n=84)$ & $71.3 \pm 14.7 * \star$ & 59. $6 \pm 22.6$ & $0.39 \pm 0.27 *$ & 5 & 18 & 24 & 37 \\
\hline Female $(n=83)$ & $75.9 \pm 15.2$ & $63.1 \pm 23.5$ & $0.29 \pm 0.26$ & 4 & 19 & 21 & 39 \\
\hline \multicolumn{8}{|l|}{ Age range } \\
\hline $40-49(n=10)$ & $69.3 \pm 13.8$ & $59.0 \pm 26.2$ & $0.43 \pm 0.15$ & 0 & 2 & 1 & 7 \\
\hline $50-59(n=71)$ & $73.2 \pm 15.6$ & $59.3 \pm 23.5$ & $0.38 \pm 0.26$ & 5 & 19 & 19 & 28 \\
\hline $60-69(n=74)$ & $75.1 \pm 15.1$ & $62.5 \pm 23.1$ & $0.31 \pm 0.29$ & 4 & 13 & 21 & 36 \\
\hline$\geq 70(n=12)$ & $71.9 \pm 14.3$ & $63.7 \pm 23.2$ & $0.28 \pm 0.26$ & 0 & 3 & 4 & 5 \\
\hline \multicolumn{8}{|l|}{ Education } \\
\hline Illiterate $(n=49)$ & $74.3 \pm 16.1$ & $64.3 \pm 24.4$ & $0.26 \pm 0.21 * \star$ & 5 & 6 & 16 & 22 \\
\hline Primary school $(n=51)$ & $76.0 \pm 14.3$ & $63.5 \pm 22.4$ & $0.35 \pm 0.25$ & 1 & 16 & 11 & 23 \\
\hline Middle school $(n=55)$ & $71.5 \pm 15.2$ & $57.6 \pm 23.0$ & $0.39 \pm 0.27$ & 1 & 13 & 16 & 25 \\
\hline$\geq$ High school $(n=12)$ & $72.8 \pm 15.2$ & $56.6 \pm 20.0$ & $0.44 \pm 0.24$ & 2 & 2 & 2 & 6 \\
\hline \multicolumn{8}{|l|}{ Marital status } \\
\hline Single $(n=18)$ & $74.9 \pm 15.3$ & $67.8 \pm 25.7$ & $0.30 \pm 0.29$ & 0 & 4 & 6 & 8 \\
\hline Married $(n=149)$ & $73.7 \pm 15.3$ & $60.4 \pm 22.5$ & $0.35 \pm 0.27$ & 9 & 33 & 39 & 68 \\
\hline \multicolumn{8}{|l|}{ Occupation } \\
\hline Farmer $(n=158)$ & $74.2 \pm 15.3$ & $62.8 \pm 23.1$ & $0.32 \pm 0.27 * \star$ & 9 & 32 & 44 & 73 \\
\hline Others $(n=9)$ & $68.4 \pm 11.5$ & $45.7 \pm 16.6$ ** & $0.54 \pm 0.18$ & 0 & 5 & 1 & 3 \\
\hline \multicolumn{8}{|l|}{ Grade of KBD } \\
\hline Grade I $(n=80)$ & $71.4 \pm 13.4$ * & $60.9 \pm 22.7$ & $0.45 \pm 0.24 * *$ & 4 & 18 & 21 & 37 \\
\hline Grade $\otimes(n=72)$ & $74.7 \pm 16.5$ & $62.6 \pm 24.2$ & $0.29 \pm 0.27$ & 4 & 16 & 19 & 33 \\
\hline Grade $\otimes(n=15)$ & $80.3 \pm 13.8$ & $61.7 \pm 26.1$ & $0.15 \pm 0.30$ & 1 & 3 & 5 & 6 \\
\hline
\end{tabular}

${ }^{*} p$ value $<0.05,{ }^{* *} p$ value $<0.01$

\section{Figures}




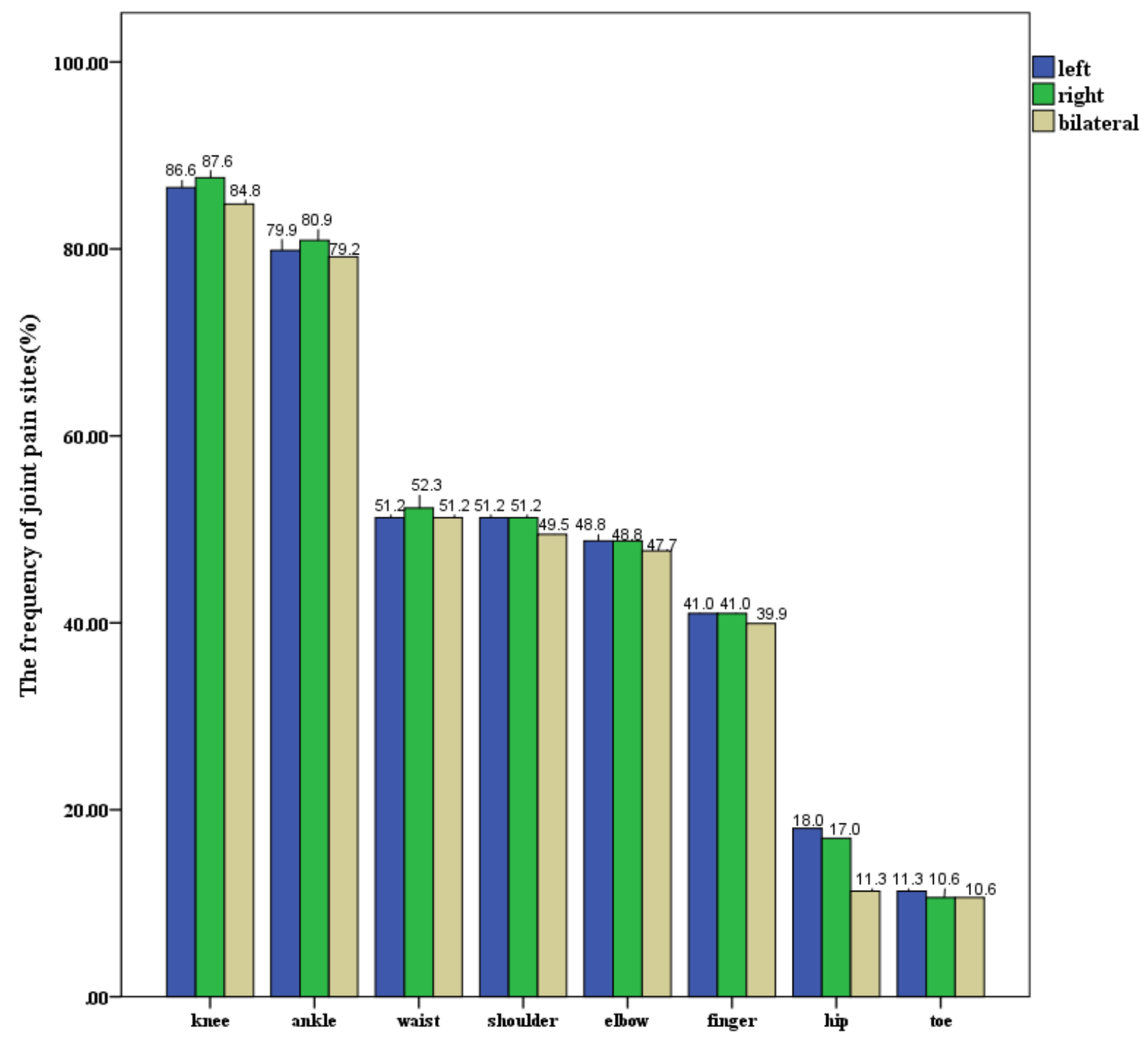

Fig. 1 The frequency of joint pain sites in the KBD group

Figure 1

The frequency of joint pain sites in the KBD group. 


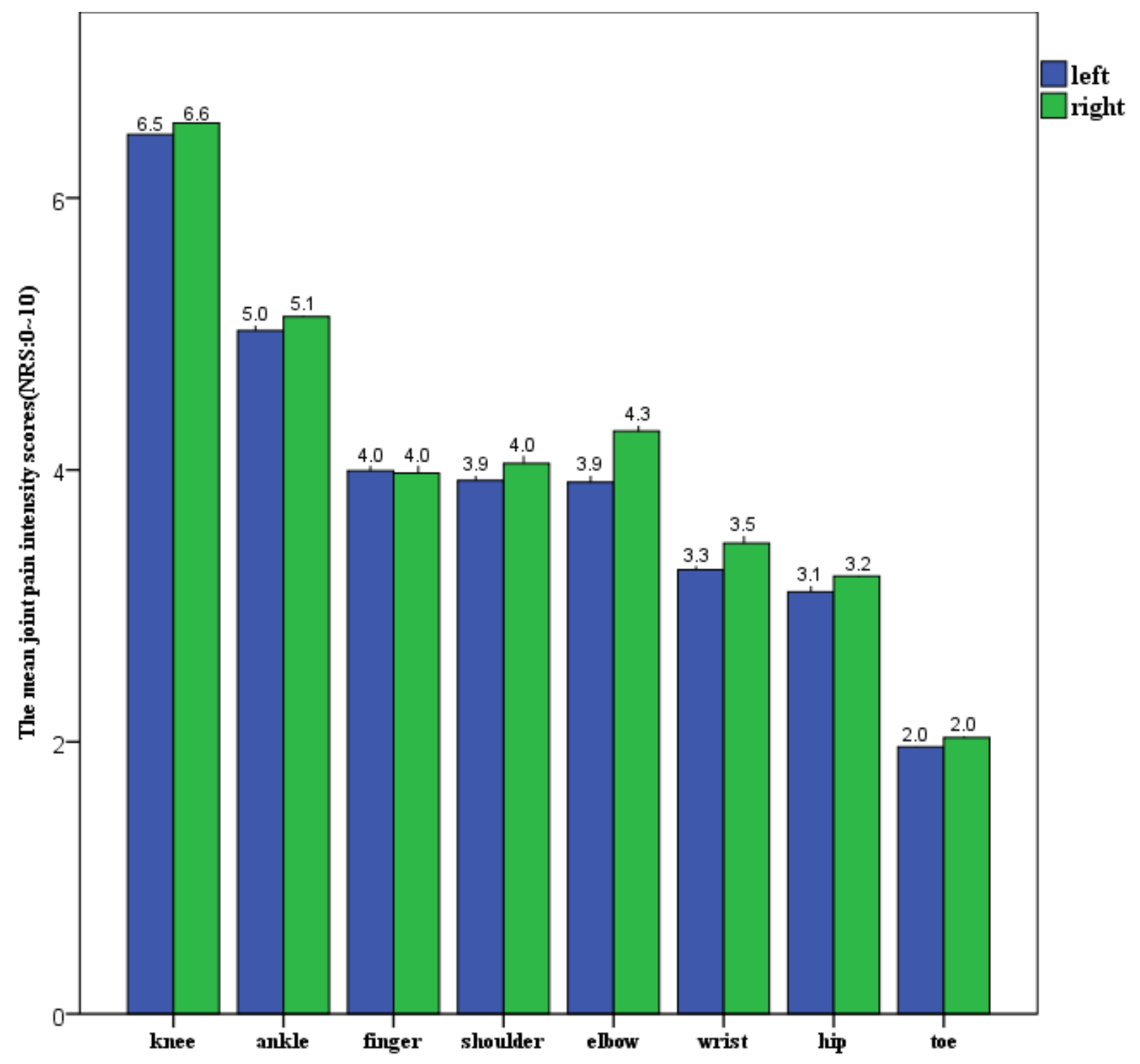

Fig.2 The mean joint pain inensity in the KBD group

\section{Figure 2}

The mean joint pain inensity in the KBD group. 